\title{
Quantification and characterization of the sludge generated from synthetic acid mine drainage treatment using sodium ferrate (VI) as an advance oxidation process
}

\author{
Alexis Munyengabe ${ }^{\mathrm{a}}$, Caliphs Zvinowanda ${ }^{\mathrm{a} 1}$, James Ramontja ${ }^{\mathrm{a}}$, John Ngoni Zvimba ${ }^{\mathrm{b}}$ \\ 218071407@student.uj.ac.za, czvinowanda@uj.ac.za, jamesr@uj.ac.za, johnz@wrc.org.za
}

\author{
${ }^{a}$ University of Johannesburg, Faculty of Science, Doornfontein Campus, Department of Chemical Sciences, \\ Corner Nind and Beit Streets, P O Box 17011, Johannesburg, South Africa, 2028 \\ ${ }^{\mathrm{b}}$ Water Use and Waste Management, Water Research Commission, Bloukrans Building, Lynnwood Bridge \\ Office Park, 4 Daventry Street, Lynnwood Manor, South Africa.
}

\begin{abstract}
A major problem in the active treatment of acid mine drainage (AMD) is the generation of large volumes of sludge through $\mathrm{pH}$ neutralization, oxidation of iron (II) and subsequent metal precipitation. The sludge settling rate, sludge volume index (SVI) and sedimentation process are ones of parameters identifying a good treatment of AMD. Sodium ferrate (VI) $\left(\mathrm{Na}_{2} \mathrm{FeO}_{4}\right)$ is one reagent currently used to treat water due to its quick reaction rate, easy implementation and relatively low chemical and operational costs. However, very limited information is available in the literature related to the detailed characterization and dewaterability of $\mathrm{Na}_{2} \mathrm{FeO}_{4}$-treated AMD sludge. This study aimed at characterizing and monitoring settling rate and densification process of synthetic AMD sludge after treatment with $\mathrm{Na}_{2} \mathrm{FeO}_{4}$. The results confirmed a complete removal of iron from the synthetic AMD due to high oxidation strength of ferrate $(\mathrm{VI})$ in acidic medium $\left(\mathrm{E}^{\mathrm{o}}=2.2 \mathrm{~V}\right)$ and showed the presence of different minerals formed in the sludge after treatment. The concentrations of the sludge collected at different intervals were justified by the densification process and high density of the sludge was obtained after 25 minutes while high weight percent of iron was found at $10 \mathrm{~min}$ and $\mathrm{Fe}$ and $\mathrm{O}$ dominated other elements in the sludge. The study demonstrated very good settling properties of the sludge and the low SVI value ranging between 30 and $60 \mathrm{~mL} / \mathrm{g}$ TSS.
\end{abstract}

Keywords: Advanced oxidation Process; Sodium ferrate (VI); Synthetic AMD; Characterization; sludge settling rate; sludge volume index

\section{INTRODUCTION}

${ }^{1}$ Corresponding author: czvinowanda@uj.ac.za 
Acidic wastewater rich in sulphur is a by-product of galvanic processing and the cleaning of flue gases at the power plants (Johnson, 2000). However, the major producer of such wastewater runoff is the mining industry. Such effluents naturally cause a threat to the environment due to high concentrations of toxic and trace metals. The main cause is the constant oxidation of iron in pyrite ore as well as in the other sulphide minerals resulting from their exposure to the oxygenated water during mining and processing of coals and precious metals (Johnson, 2003). Two remediation methods are known for this type of water normally called acid mine drainage (AMD). These include abiotic and biological technologies. Each system comprises two processes, namely, active and passive treatments. The active treatment method uses energy during the process of air pumping through the AMD and lime addition rendering it to be expensive while passive treatment is a new technology working without the requirement of mechanical equipment, electrical power, hazardous chemicals, or buildings, daily maintenance and operation. They are also more aesthetic and natural in their appearance and may support wildlife and plants. They involve using anoxic limestone and sulphatereducing bacteria or both to precipitate metals and neutralize acidity. These systems are sometimes described as bioreactors or wetlands. All these advantages make it less expensive compared to active treatment method has been chosen by the Bureau of Land Management (Ford, 2003). In this study, a new active treatment process was used to remove metals such as Iron and to neutralize the acidity of AMD using in-situ liquid sodium ferrate (VI) without using energy during the oxidation process and lime to neutralize the acidity. Oxidizing reagents such as ozone, free radicals, chromate and permanganate salts have also been used to remove it from wastewater and mine water as ferric hydroxide through precipitation process. Biologically, compost bioreactors, packed bed-iron oxidation bioreactors and permeable reactive barriers are frequently used to remove metals from AMD as passive systems (Johnson, \& Hallberg, 2005; Bailey, 2018). However, different studies have been conducted to remove or recover heavy metals such as Fe from water using passive and active methods, but no research was conducted to evaluate the settleability, quantity and composition of the sludge formed during its oxidation (Seo et al., 2017; Samal et al., 2020). In this regard, a vertical flow reactor (VFR) technique i.e., measuring cylinder in this study, which works under aerobic conditions to oxidize $\mathrm{Fe}^{2+}$ from wastewater and water has been proposed to be applied for monitoring the sludge settling rate during its oxidation by sodium ferrate (VI). The removal of $\mathrm{Fe}^{2+}$ in the earlier VFR systems was performed by precipitation of $\mathrm{Fe}$ (III) minerals, heterogeneous oxidation of $\mathrm{Fe}^{2+}$ by ferrate (VI) ions and filtration of ferric hydroxides that are produced in the water column (Florence et al., 2016). The effectiveness of sludge settling depends on many factors, for instance, 
hydrodynamics and settling behavior of the sludge. This settling behavior depends on the flocculation tendency of suspended solids and sludge concentration throughout the system (Erdincler, \&Vesilind, 2003). Accordingly, four classes during settling can be illustrated including the discrete settling regime, discrete flocculent settling, hindered settling, and compression phase (Ekama et al., 1997, Mazdeh, 2014). This paper aims at exploring the removal of $\mathrm{Fe}^{2+}$ by sodium ferrate (VI) as an eco-friendly emerging water treatment oxidant without filtration, studying and characterizing the sludge settling rate formed in a VFR system at a low $\mathrm{pH}$ value.

\section{MATERIALS AND METHODS}

\subsection{Reagents}

Potassium ferrate (VI) (>96\%) was purchased from America Elements (USA) while other salts used to prepare a synthetic AMD solution were purchased from Sigma-Aldrich, UK.

\subsection{Preparation of synthetic AMD solution}

A $1 \mathrm{~L}$ of synthetic AMD solution containing $\mathrm{Al}, \mathrm{Fe}, \mathrm{Mn}, \mathrm{Zn}, \mathrm{Ni}$ and $\mathrm{Mg}$ was prepared using ultrapure water. The $\mathrm{pH}$ of the synthetic AMD solution was maintained at 3 using $2 \mathrm{M} \mathrm{H}_{2} \mathrm{SO}_{4}$ to prevent immediate precipitation of ferric hydroxide (Munyengabe et al., 2020).

\subsection{Preparation of sodium ferrate (VI)}

A wet oxidation method was used to produce liquid sodium ferrate (VI) using liquid sodium hypochlorite $(15 \%)$, sodium hydroxide $(43 \%)$ and ferric chloride $(43 \%)$ in the ratio of 10:5:1 v/v (Munyengabe, \& Zvinowanda, 2019). An overall Equation 1 of formation of $\mathrm{Na}_{2} \mathrm{FeO}_{4}$ that was first described by Thompson et al. (1951) has been taken into consideration in this work.

$$
3 \mathrm{NaOCl}_{(\mathrm{aq})}+10 \mathrm{NaOH}_{(\mathrm{aq})}+2 \mathrm{FeCl}_{3(\mathrm{aq})} \rightarrow 2 \mathrm{Na}_{2} \mathrm{FeO}_{4(\mathrm{aq})}+9 \mathrm{NaCl}_{(\mathrm{aq})}+5 \mathrm{H}_{2} \mathrm{O}_{(\mathrm{l})}
$$

The working calibration curve ranging from 0 to $50 \mathrm{mg} / \mathrm{L}$ was prepared using potassium ferrate $\left(\mathrm{FeO}_{4}{ }^{2-}\right)(\mathrm{VI})$ as a standard. The concentration of liquid $\mathrm{Na}_{2} \mathrm{FeO}_{4}$ was further determined using UV-Vis spectrophotometer, Cary $60\left(\lambda_{\max }=510 \mathrm{~nm}\right.$ for $\left.\mathrm{FeO}_{4}{ }^{2-}\right)$ (Munyengabe, \& Zvinowanda, 2019).

\subsection{Optimum conditions}


Operating optimum conditions for oxidation of $\mathrm{Fe}^{2+}$ including the effect of volumes of $\mathrm{Fe}^{2+}$ solution and ferrate (VI), contact time, $\mathrm{pH}$, and initial concentrations of ferrate are presented in Table 1 (Munyengabe et al., 2020).

Table 1: Optimum conditions

\begin{tabular}{ccccc}
\hline $\begin{array}{c}\text { Time } \\
(\mathrm{min})\end{array}$ & $\mathrm{pH}$ & $\begin{array}{c}{\left[\mathrm{FO}_{4}{ }^{2-}\right]} \\
(\mathrm{mmol} / \mathrm{L})\end{array}$ & $\begin{array}{c}\text { Volume of } \mathrm{Fe}^{2+} \\
\text { solution } \\
(\mathrm{mL})\end{array}$ & $\begin{array}{c}\text { Volume of ferrate solution } \\
(\mathrm{mL})\end{array}$ \\
\hline 30 & 3.0 & $5.0 \times 10^{-2}$ & 15 & 5 \\
\hline
\end{tabular}

\subsection{ANALYTICAL METHODS}

3.1 Inductively coupled plasma-optical emission spectroscopy (ICP-OES) analysis

The concentrations of metals were determined using ICP-OES (iCap 6500 Duo, Thermo Scientific, UK) before and after oxidation process to check if ferrate (VI) ions could reduce or completely remove them from synthetic AMD. The main target elements to be removed in this study were Fe, Mn and Zn. Iron was selected during AMD treatment as it is the main element causing the acidity in this type of water during its oxidation while $\mathrm{Mn}$ and $\mathrm{Zn}$ are barely removed from the water at $\mathrm{pH}$ less than 9.5. Before oxidation process, synthetic AMD (ca. 400 $\mathrm{mg} \mathrm{Fe}{ }^{2+} / \mathrm{L}$ ) was diluted to 100 times by taking $1 \mathrm{~mL}$ of the sample into $99 \mathrm{~mL}$ of deionized water and filtered at $0.22 \mu \mathrm{m}$. The calibration curve ranging from 0 to $7.5 \mathrm{mg} / \mathrm{L}$ for all metals was prepared using a multielement standard solution. Treated synthetic AMD was first centrifuged and the supernatant liquid was filtered using the same size of filters. All samples were run in triplicate on ICP-OES.

3.2 UV-Vis spectroscopic analysis

Concentrations of $\mathrm{Fe}^{2+}$ in synthetic AMD during oxidation with ferrate using UV-Vis spectroscopy. However, the results showed that $\mathrm{Fe}^{2+}$ can be oxidized by ferrate ions at the oxidation rate of $99.95 \%$ in $30 \mathrm{~min}$ at $\mathrm{pH}=3$. Both the concentrations of $\mathrm{Fe}^{2+}$ (complexed with 1, 10-phenanthroline) and ferrate (VI) solution were determined using UV-Vis spectrophotometer. 


\subsection{Total suspended solids}

The concentrations of total suspended solids (TSS) or sludge were measured after oxidation and precipitation processes of metals in a synthetic AMD by filtering water sample through cellulose filter papers and dried at ambient temperature to avoid heat degradation. The sludge was kept inside the desiccator for further analysis.

\subsection{Sludge volume index (SVI)}

Two parameters commonly used to quantify the settling of the sludge are the zone settling rate and the sludge volume index (SVI). The SVI is the volume occupied by $1 \mathrm{~g}$ of sludge after 30 min of settling in a $1000 \mathrm{~mL}$ unstirred cylinder. Many researchers recognize SVI as the best parameter characterizing the sludge settling properties. The SVI is also a good indicator of sludge bulking. Practically, the SVI can vary from 30 to $400 \mathrm{~mL} / \mathrm{g}$ where $30 \mathrm{~mL} / \mathrm{g}$ indicates a sample with very good settleability and $400 \mathrm{~mL} / \mathrm{g}$ a sample with poor settling properties (Janczukowicz et al., 2001). In other words, if the SVI is less than 60 the sludge is settling too fast and if above 150 the sludge is bulking. It was obtained by dividing the settled volume of sludge $\left(\mathrm{SV}_{30}\right.$ in $\left.\mathrm{mL} / \mathrm{L}\right)$ with the concentration of sludge or TSS $(\mathrm{g} / \mathrm{L})$. The volume of the sludge after 30 min of settling was used to calculate the SVI value using the Equation 2 where MLSS is the concentration of the sludge, or the mixed liquor suspended solids:

SVI $(\mathrm{mL} / \mathrm{mg})=$ settled sludge volume $(\mathrm{mL} / \mathrm{L}) / \mathrm{MLSS}(\mathrm{mg} / \mathrm{L})$

\subsection{Chemical analysis of the sludge}

Dried sludge samples were taken from the desiccator and subjected to Fourier TransformInfrared (FT-IR), X-Ray Diffraction (XRD) and SEM-EDS to determine the crystallinity of the precipitates, density and the chemical composition or mineralogy of the sludge, respectively.

\section{RESULTS AND DISCUSSIONS}

\subsection{Oxidation rate of ferrous ions in synthetic AMD}

The oxidation rate of ferrous ions in synthetic AMD was calculated by dividing its final concentration $(0.02 \mathrm{mg} / \mathrm{L})$ with the initial concentration $(400.00 \mathrm{mg} / \mathrm{L})$ obtained using $\mathrm{UV}-\mathrm{V}$ is spectroscopy and multiplied by 100 . However, the oxidation rate of ferrous ions in synthetic AMD was found to be $99.95 \%$. 


\subsection{ICP-OES results}

Table 2: Initial and residual concentrations of metals

\begin{tabular}{ccc}
\hline Metal ions & $\begin{array}{r}\text { Initial concentration } \\
(\mathrm{mg} / \mathrm{L})\end{array}$ & $\begin{array}{c}\text { Final concentration } \\
(\mathrm{mg} / \mathrm{L})\end{array}$ \\
\hline $\mathrm{Fe}(\mathrm{II})$ & 400.00 & 0.0 \\
$\mathrm{Cu}(\mathrm{II})$ & 0.90 & 0.0 \\
$\mathrm{Ni}(\mathrm{II})$ & 0.20 & 0.0 \\
$\mathrm{Al}(\mathrm{III})$ & 40.50 & 0.0 \\
$\mathrm{Mg}(\mathrm{II})$ & 36.8 & 0.0 \\
$\mathrm{Mn}(\mathrm{II})$ & 0.8 & 0.0 \\
$\mathrm{Zn}(\mathrm{II})$ & 11.5 & 0.1 \\
\hline
\end{tabular}

Besides complete removal of $\mathrm{Fe}^{2+}$, these results showed that our targeted metals especially $\mathrm{Mn}$ and $\mathrm{Zn}$ also can be reduced or completely removed by this emerging oxidizing and coagulating agent from the synthetic AMD as the resulting $\mathrm{pH}$ was greater than 9. The results also confirmed the complete removal of $\mathrm{Fe}^{2+}$ through oxidation process from synthetic AMD as shown with the UV-Vis spectroscopic results. In this regard, ferrate (VI) confirmed to be a promising oxidant, flocculent and coagulant and no harmful by-products are formed in its selfdecomposition to Fe (III) hydroxides and oxides.

4.3 Sludge settling rate and interpretation of the batch settling curve

According to Figure 1, the sludge settling rate was very high in 30 minutes and a small increment was observed after 5 hours with intense clarification of the supernatant liquid. This kind of settleability of the formed sludge from the oxidation of ferrous ions and selfdecomposition of the liquid ferrate into ferric hydroxides confirms the coagulating activity of this oxidant during AMD treatment at low $\mathrm{pH}$ values. 


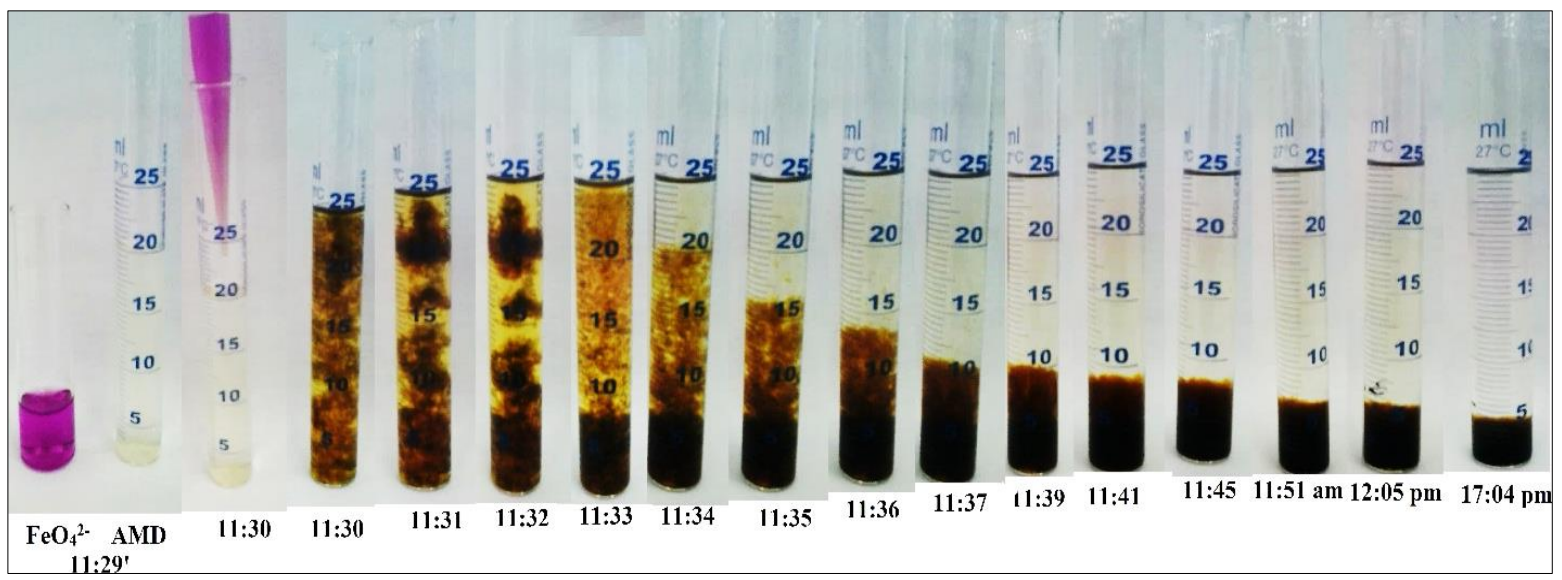

Figure 1: Time sequence images of the sludge settling rate in an unstirred measuring cylinder

By using a ruler, the initial length of the liquid in the measuring cylinder $(25 \mathrm{~mL})$ was deduced and found to be $9.70 \mathrm{~cm}(0.097 \mathrm{~m})$ and sequence lengths are also provided in Table 3.

Table 3: Summary of the results from sludge settlement

\begin{tabular}{cccc}
\hline Sequences & $\begin{array}{c}\text { Time } \\
(\text { hour })\end{array}$ & $\begin{array}{c}\text { Distance } \\
(\mathrm{m})\end{array}$ & $\begin{array}{c}\text { Velocity } \\
(\mathrm{m} / \mathrm{h})\end{array}$ \\
\hline 1 & 0 & 0.097 & 0 \\
2 & 0.03 & 0.097 & 3.23 \\
3 & 0.03 & 0.021 & 0.70 \\
4 & 0.01 & 0.014 & 1.45 \\
5 & 0.01 & 0.015 & 1.50 \\
6 & 0.06 & 0.009 & 0.15 \\
7 & 0.06 & 0.008 & 0.13 \\
8 & 0.30 & 0.005 & 0.02 \\
9 & 4.88 & 0.006 & 0.00 \\
\hline
\end{tabular}

From Table 3, the initial rapid linear settling behavior slowed quickly and stabilized after 4.88 hours. Mean settling velocity of $1.02 \mathrm{~m} / \mathrm{h}$ was then recorded within the first $30 \mathrm{~min}$ of the sludge settling test and the settling zones are presented in Figure 2. 


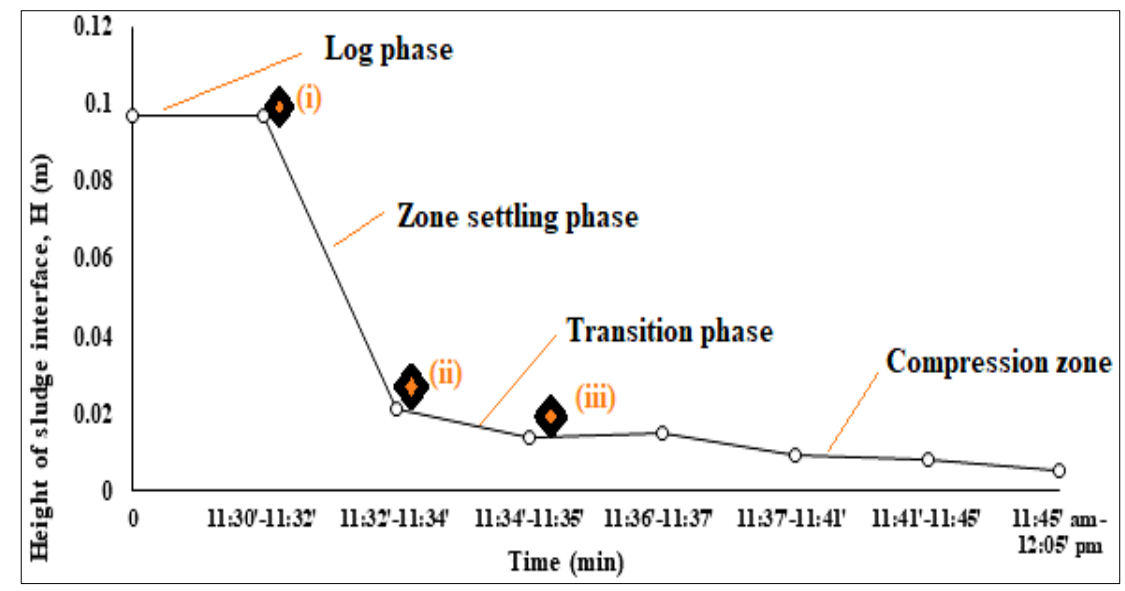

Figure 2: Sludge blanket height (m) vs time (min) indicating four phases (Rushton et al., 2008)

During sludge settling process, four phases are subsequently expected to happen on every batch settling graph and each phase normally shows the variation in the settling behavior at the suspension-liquid interface (Torfs et al., 2016). However, Figure 2 indicates that in the first four (1, 2, 3 and 4) sequences (see Table 5.4), the sludge settling velocity was increasing (considered as a log phase) and started decreasing after in the next 5, 6 and 7 sequences (zone settling, transition and compression phases) and became stable after 5 hours (Rushton et al., 2008). As the oxidation takes place, the sludge settling velocity increases due to the production of ferric ions and decreases during the coagulation process.

\section{QUANTIFICATIONS OF THE SYNTHETIC AMD SLUDGE}

\subsection{Suspended solids (SS) concentration}

Masses of the produced sludge, volume of synthetic AMD solution, and calculated concentration of total SS are all presented in Table 4.

Table 4: Summary of mass, volume and concentration of synthetic AMD sludge

\begin{tabular}{cccc}
\hline $\begin{array}{c}\text { Time } \\
(\min )\end{array}$ & $\begin{array}{c}\text { Mass of the sludge } \\
(\mathrm{g})\end{array}$ & $\begin{array}{c}\text { Volume of synthetic AMD } \\
(\mathrm{L})\end{array}$ & $\begin{array}{c}\text { Concentration } \\
(\mathrm{g} / \mathrm{L} \text { TSS })\end{array}$ \\
\hline 5 & 0.0452 & 0.025 & 1.81 \\
10 & 0.2386 & 0.025 & 9.54 \\
15 & 0.1495 & 0.025 & 5.98 \\
20 & 0.1122 & 0.025 & 4.50 \\
25 & 0.3033 & 0.025 & 12.13
\end{tabular}


The concentrations of suspended solids (SS) of synthetic AMD sludge ranged between 1.80 and $12.13 \mathrm{~g} / \mathrm{L}$. Similar range concentrations of SS of different sludges generated from treatment of AMD have been found in the literature (Janczukowicz et al., 2001; Uchiyama et al., 2007). According to the settling behavior of a suspension process, Figure 3 generated from Table 5, can be divided into three main sedimentation or flocculation parts. The first part is between 5 and $10 \mathrm{~min}$, the second part is between 15 and $20 \mathrm{~min}$ and the last part is between 25 and 30 $\min$.

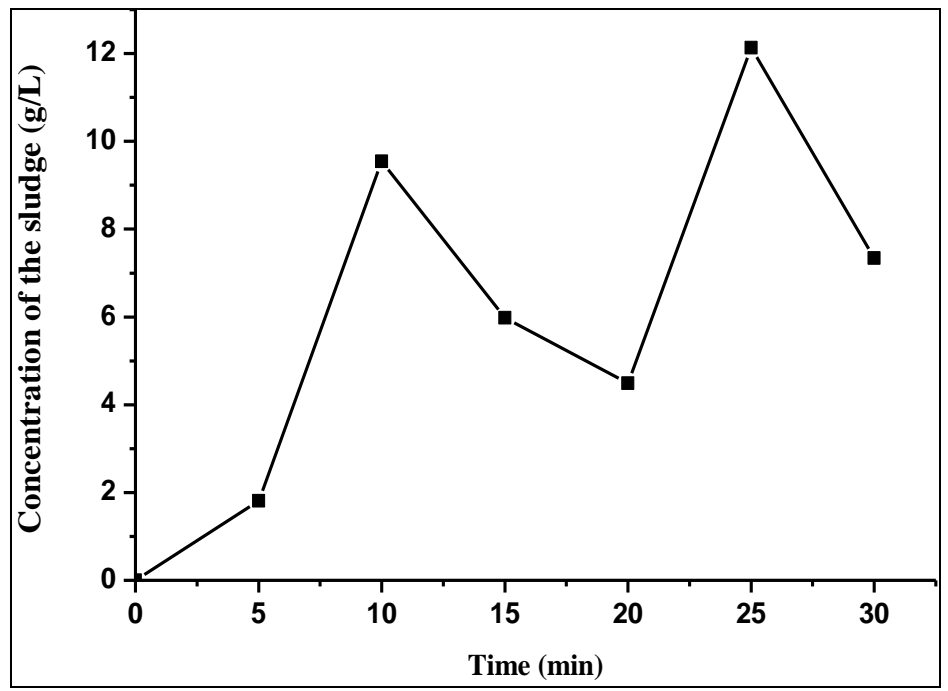

Figure 3: Concentration of the sludge vs time

The first part of Figure 3 combines two phases including discrete non-flocculent settling or Class A and discrete flocculent settling or Class B (5-10 min). The second part comprises the hindered settling or zone settling or Class C (15-20 min) while the third part indicates the compressive settling or Class D (25-30 min). In brief, at first two classes A and B (low concentrations), the particles are scattered and there is no physical contact between them. Characteristically, the concentration is too diluted to further influence the settling behavior of particles. Though each particle can settle at its distinctive terminal velocity, and this depends on individual particle properties including porosity, shape, density, and size. If dilute particles do not show any tendency to flocculate, thus, this regime is referred to as discrete nonflocculent settling (Class A) (Ekama et al., 1997). Through successive processes of cohesion and collision, larger particles are formed causing their settling rate to change over time and, however, this regime is ascribed as discrete flocculent settling (Class B) where the formed particles still settle at their characteristic terminal rate. Classes A and B undergo principally 
the same settling dynamics. The difference only lies in the fact that for class B, extra flocculation process occurs concurrently with the settling process, which modifies the individual properties of particles and accordingly their terminal settling rate. The transition from class B to C occurs if the suspended solid concentrations in the container exceed threshold concentrations where the particles are no longer settling separately from one another. For secondary sludge, the transition characteristically occurs at concentrations between 0.60 and $0.70 \mathrm{~g} / \mathrm{L}$ while for granular sludge the threshold concentrations can go up to $1.60-5.50 \mathrm{~g} / \mathrm{L}$ depending on the granulation state (Mancell-Egala, Kinnear, Murthy, \& Jones, 2012). Above this range, each particle is hindered by the other particles and the inter-particle forces are adequately strong to drag each particle along at the same rate, regardless of the density and size. In other words, the particles settle together as a zone, and consequently, this regime is called zone settling in which a distinct interface between the subsiding particles and the clear supernatant is formed. When suspended solid concentration further increases above a critical concentration ranging between 5 and $10 \mathrm{~g} / \mathrm{L}$ ), the settling behavior changes to compressive settling or Class D. The exact transition concentration depends once more on the flocculation state of the particles (De Clercq et al., 2008). At these higher concentrations, the suspended solids come into physical contact with one another and are subject to compaction due to the weight of overlying particles and the settling rate will be much lower than in class $\mathrm{C}$ regime.

\subsection{Sludge volume index (SVI)}

In this study, the settled sludge volume was approximately $6.30 \mathrm{~mL} / 25 \mathrm{~mL}$ from Figure 1 , which was taken up to $1000 \mathrm{~mL}$ (normal size of measuring cylinder for SVI studies), which has become around $252 \mathrm{~mL} / \mathrm{L}$. By applying the formula of SVI, the value of SVI obtained was then $34.33 \mathrm{~mL} / \mathrm{g}$ in $30 \mathrm{~min}\left(\mathrm{SVI}_{30}\right)$. This SVI indicated a sludge with good settling properties according to its variation range. The study exposed very good settling properties of the sludge and the low SVI value ranging between 30 and $60 \mathrm{~mL} / \mathrm{g}$ TSS was responsible for intensive and quick sedimentation, which has shortened the settle phase to less than $60 \mathrm{~min}$. In conclusion from Figure 1 and the results obtained in this study, the formation of the sludge was highly characterized by high sludge settling velocity, low settling sludge volume and the relatively high settled solid concentration. 


\section{CHARACTERIZATION OF THE SLUDGE}

\subsection{FT-IR spectroscopic method}

Figure 4 shows different transmittances and absorptions of sludge collected over time $(5,10$, 15, 20, 25, and $30 \mathrm{~min}$ ). The transmittances of sludge observed after $5 \mathrm{~min}$ (blue line) were higher than other sludge densities. This indicates that this sludge is less dense while the sludge collected after 10 (pink line) and 25 min (black line) were denser than others. This highly correlates with their calculated concentrations provided in Table 5 and Figure 4, which goes together with the settling behavior of a suspension process. Different sludge produced and collected at different times with an interval of $5 \mathrm{~min}$, were analyzed using FT-IR instrument to determine their densities and concentrations. The peaks of different functional groups of minerals formed during settlement and flocculation are shown in Figure 4.

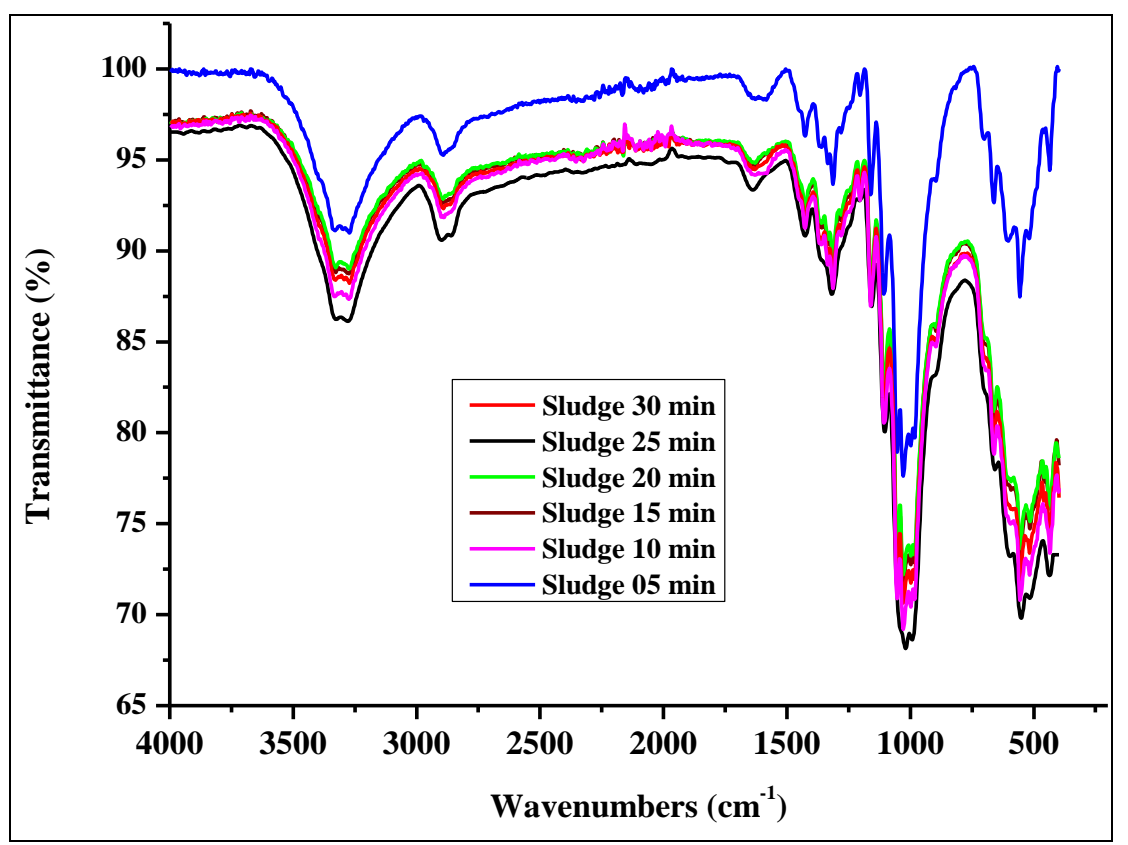

Figure 4: Different spectra of sludge collected after 5, 10, 15, 20, 25, and $30 \mathrm{~min}$

The FT-IR spectra confirm the formation and presence of different minerals in the sludge produced during the experiment. The valuable peaks are $432.18 \mathrm{~cm}^{-1}$ could be attributed to the doubly degenerate $v_{2} \mathrm{SO}_{4}{ }^{2-}$ bending mode (Frost, Xi, \& Scholz, 2013; Flores et al., 2019). The peaks found at $554.82 \mathrm{~cm}^{-1}$ are attributable to the metal oxides such as $\mathrm{Fe}-\mathrm{O}$ (iron oxide minerals), the peaks $1025.73 \mathrm{~cm}^{-1}$ corresponds to $v_{3} \mathrm{SO}_{4}{ }^{2-}$, and $1636.33 \mathrm{~cm}^{-1}$ might correspond to $\delta \mathrm{H}_{2} \mathrm{O}$ of the jarosite mineral (Mejía et al., 2015; Flores et al., 2019). Five peaks are noted at $1104.21,1163.90,1314.32,1432.05,2894.66$, and $3301.80 \mathrm{~cm}^{-1}$ are also due to water 
stretching bands of different minerals. The observation of these multiple water stretching bands gives credence to the non-equivalence of water units in the aluminum sulphate hydrate structure which may be present in the sludge (Mejía et al., 2015). The infrared bands between 3167 and $3412 \mathrm{~cm}^{-1}$ are attributed to $v-\mathrm{OH}$ due to water in the sludge (Flores et al., 2019). The peak observed between 1000 and $1170 \mathrm{~cm}^{-1}$, with an intense band around $1015.10 \mathrm{~cm}^{-1}$ can be attributed to $\delta-\mathrm{OH}$ vibration of mineral compounds such as akageneite $\left[\mathrm{Fe}^{3+} \mathrm{O}(\mathrm{OH}, \mathrm{Cl})\right]$ and jarosite $\left[\mathrm{Fe}^{3+}{ }_{3}(\mathrm{OH})_{6}\left(\mathrm{SO}_{4}\right)_{2}\right]^{-}$, which are always present in the sludge (Francioso et al., 2010). This can be supported by the literature where Mejía et al. (2015) identified these minerals at 1190,1085 and $1008 \mathrm{~cm}^{-1}$.

\subsection{XRD analysis}

The XRD patterns of the sludge generated using ferrate (VI) ions as the oxidant and coagulant showed that the main diffraction patterns $\left(2 \theta=20-25^{\circ}\right)$ could be attributed to iron oxide and ferric hydroxide species as shown in Figure 5. Other minerals precipitated from $\mathrm{Cu}, \mathrm{Al}, \mathrm{Zn}$, or Mn were XRD amorphous due to their lower concentrations and a small amount of the sludge.

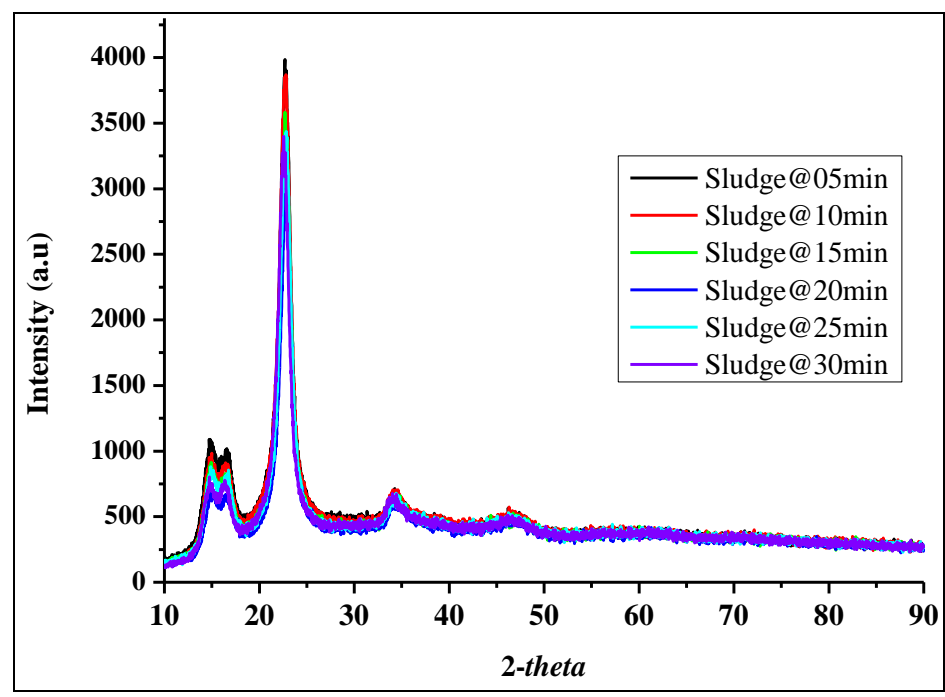

Figure 5: XRD patterns of synthetic AMD sludge

\subsection{Scanning electron microscopy (SEM)-Energy Dispersive X-ray Spectroscopy (EDS)}

The SEM analysis was used to study the morphology of the sludge collected at different intervals to determine the optimum time in which all metals have been oxidized and coprecipitated. The EDS connected to SEM assisted to determine the presence and quantity of metals (percentage) in the sludge produced between 5 and 30 minutes. Figures 6-11 [a, b, c] show the images of sludge that was studied through the SEM-EDS. 


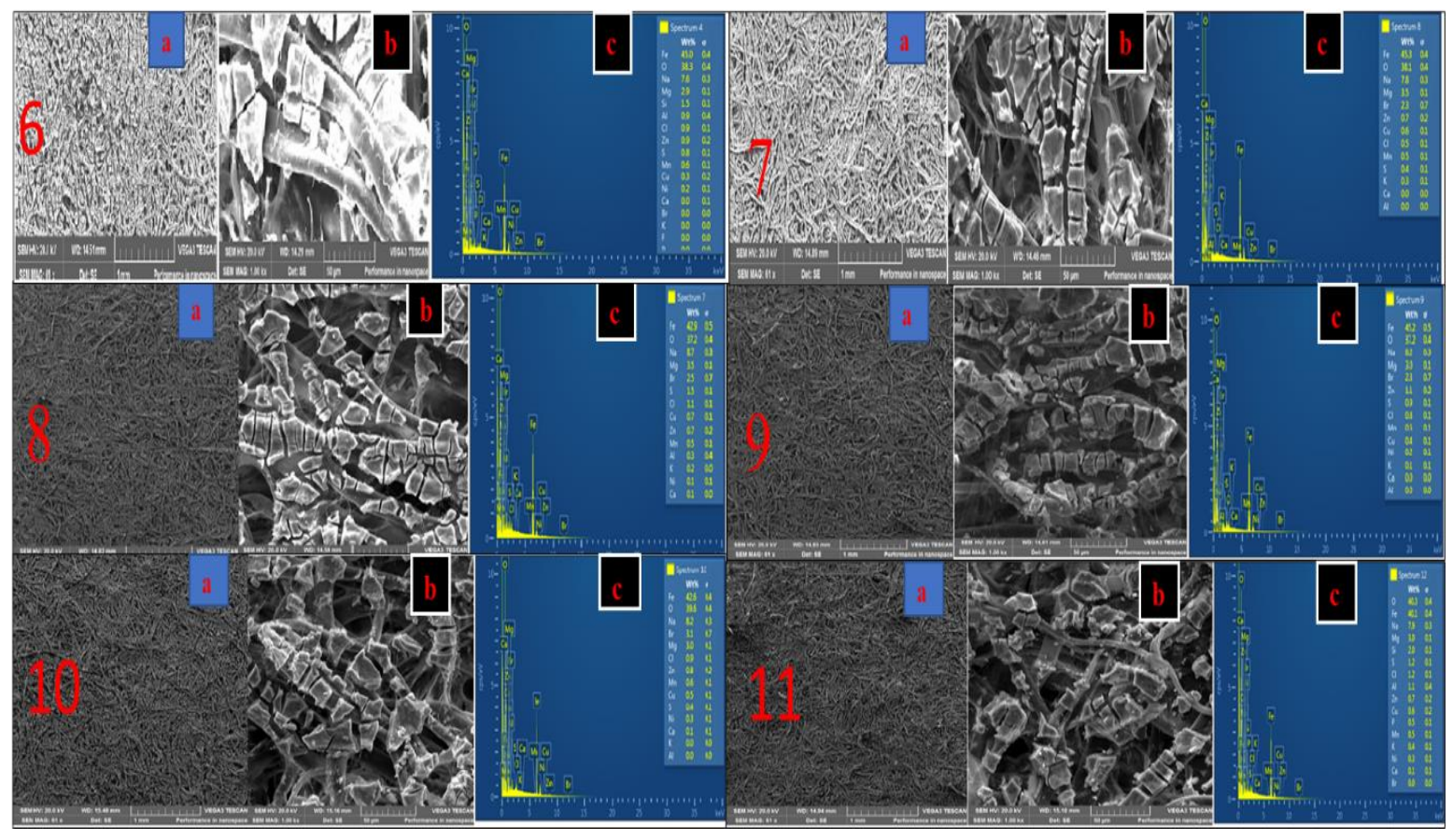

Figure 6-11: [6a,b,c]: sludge collected after $5 \mathrm{~min}$ and analyzed with SEM-EDS, [7a,b,c]: sludge collected after $10 \mathrm{~min}$, [8a,b,c]: sludge collected after $15 \mathrm{~min},[9 \mathrm{a}, \mathrm{b}, \mathrm{c}]$ : sludge collected after $20 \mathrm{~min},[10 \mathrm{a}, \mathrm{b}, \mathrm{c}]$ : sludge collected after 25 and [11a,b,c]: sludge collected after $30 \mathrm{~min}$

The images [a] from all Figures 6-11 were taken using SEM magnification of $61 \mathrm{x}$, images [b] at $1000 \mathrm{x}$ while images [c] are showing the partition percentages of all metals and non-metals composing the sludge formed between 5 and 30 minutes. Another observation from these figures is a great change of color intensity of the sludge as time varied from 5 to 30 minutes. This confirms the densification indicated by the FT-IR spectrum where low transmittances (high absorptions) were observed after 15 minutes. Sedimentation or densification might increase as time increases. The iron, oxygen and sodium showed dominance in all sludge produced confirming the precipitation of ferric hydroxide, breakdown of sodium ferrate and presence of sodium hydroxide. It can also be seen in Figure 5.12 that the amount of iron decreased with time due to densification of the sludge through precipitation of alkali and alkaline earth metals including $\mathrm{Na}$ and $\mathrm{Mg}$, and other heavy metals such as $\mathrm{Zn}$ and $\mathrm{Mn}$ which could block its detection by the instrument. 


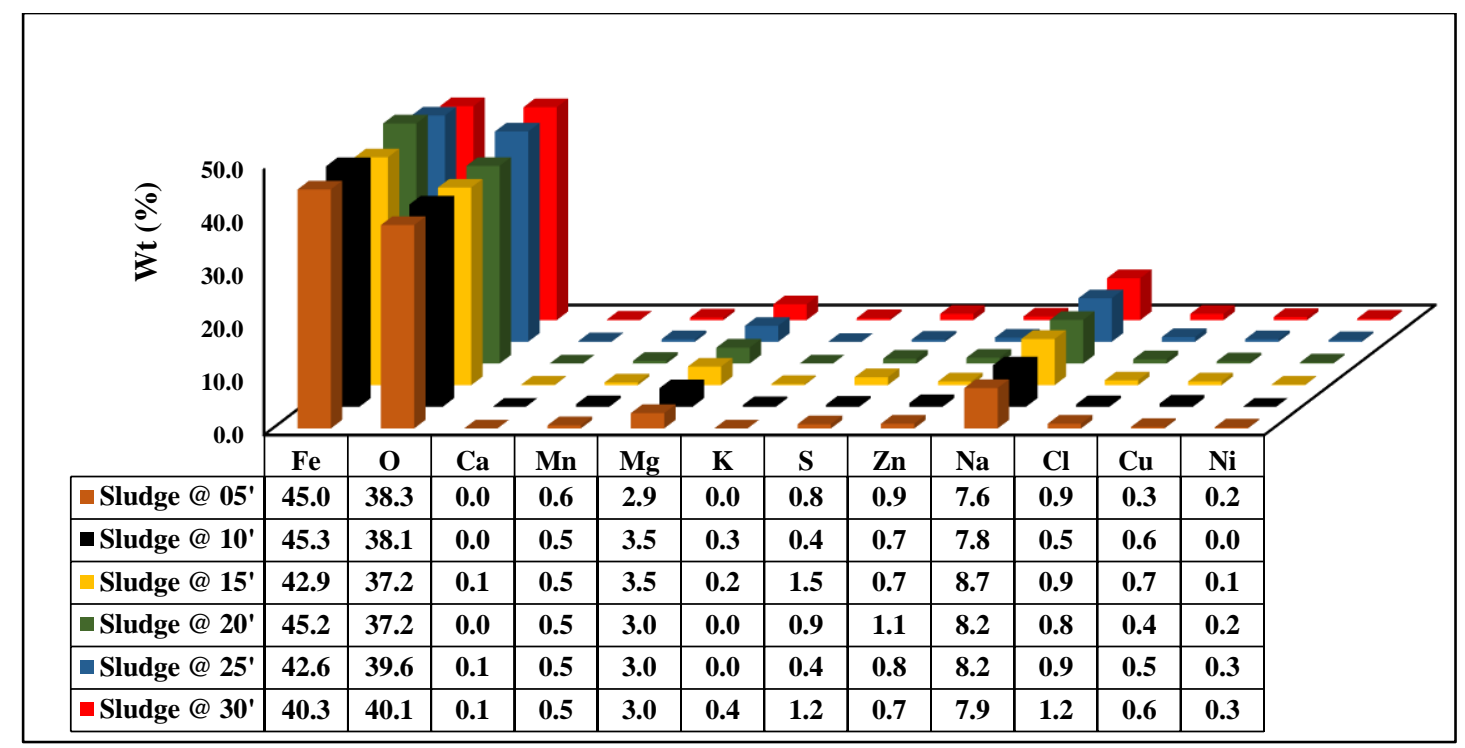

Figure 7: 3-D plot generated by EDS for the sludge deposited between 5 and 30 minutes

From Figure 12, a minimum of 15 minutes was enough for all elements to be removed from the synthetic AMD when it was treated with the novel sodium ferrate (VI).

\section{CONCLUSION}

The application of the advanced oxidation process using a green oxidant $\mathrm{Na}_{2} \mathrm{FeO}_{4}$ for the treatment of a synthetic AMD sample was performed. The results indicated that this method could be effective for ameliorating the quality of sludge generated through the oxidation process of iron (II) and removal of other metals from the AMD. Metals were removed through coagulation and co-precipitation processes due to ferric ions generated from the oxidation of iron (II) and breakdown of ferrate (VI) ions. The produced sludge was characterized by, SEMEDS, XRD and FT-IR while the concentration of metals was determined using ICP-OES and $\mathrm{UV}-\mathrm{V}$ is spectroscopy analyses. The UV-Vis analysis results confirmed with the ones of ICPOES that iron has completely removed from the synthetic AMD, which also confirmed the oxidation strength of ferrate (VI) in acidic medium $\left(\mathrm{E}^{\mathrm{o}}=2.2 \mathrm{~V}\right)$. The XRD, SEM-EDS and FTIR showed the presence of different minerals formed in the synthetic AMD sludge. The concentrations of the sludge collected at different times were justified by the densification process shown by FT-IR spectra that a high density of the sludge was obtained after $25 \mathrm{~min}$. Different quantification parameters including the sludge settling velocity, sludge volume index and zone settling rate were determined. The study exposed very good settling properties of the sludge and low SVI value ranging 30 and $60 \mathrm{~mL} / \mathrm{g}$ TSS was responsible for intensive and quick sedimentation, which shortened the settle phase to less than $60 \mathrm{~min}$. Additionally, the low SVI 
prevented the sludge from bulking. Only 15 minutes are enough for all metals to be removed from the water when it is being treated with this novel sodium ferrate (VI).

\section{ACKNOWLEDGEMENTS}

This study was supported by the University of Johannesburg (UJ) and NRF/South Africa. Many thanks to Prof. P.N. Nomngongo, and the group members from Lab 3404 (Analytical Environmental Chemistry Lab, DFC). Authors give thanks to Prof. O. Arotiba and Dr. L. Tshwenya for the assistance with FT-IR, Mrs. O. Sebabi for the assistance with XRD, Mr. S. Pole for the assistance with BET, and Mr. D. Mabu for the assistance with SEM-EDS.

\section{REFERENCES}

Bailey, M. T. (2018). Biological leaching of metal contaminated substrates from a passive bioreactor treating mine drainage. Environmental Science: Water Research and Technology, 4(5), 739-749. https://doi.org/10.1039/C8EW00055G

De Clercq, J., Nopens, I., Defrancq, J., \& Vanrolleghem, P. A. (2008). Extending and calibrating a mechanistic hindered and compression settling model for activated sludge using in-depth batch experiments. Water Research, 42(3), 781-791. https://doi.org/10.1016/j.watres.2007.08.040

Ekama, G. A., Barnard, G. L., Gunthert, F. W., Krebs, P., McCorquodale, J. A., Parker, D. S., \& Wahlberg, E. J. (1997). Secondary settling tanks. London: International Association on Water Quality. https://www.iwapublishing.com/books/9781900222037/secondary$\underline{\text { settling-tanks }}$

Erdincler, A., \& Vesilind, P. A. (2003). Effect of sludge water distribution on the liquid-solid separation of biological sludge. Journal of Environmental Science and Health, Part A, 38(10), 2391-2400. https://doi.org/10.1081/ESE-120023439

Florence, K., Sapsford, D. J., Johnson, D. B., Kay, C. M., \& Wolkersdorfer, C. (2016). Ironmineral accretion from acid mine drainage and its application in passive treatment. $\begin{array}{lll}\text { Environmental Technology, } & \text { 37(11), }\end{array}$ https://doi.org/10.1080/09593330.2015.1118558

Flores, M. U., Reyes, I. A., Palacios, E. G., Patiño, F., Juárez, J. C., Reyes, M., \& Gutiérrez, E. J. (2019). Kinetic Analysis of the Thermal Decomposition of a Synthetic Mercury Jarosite. Minerals, 9(4), 200. https://doi.org/10.3390/min9040200

Ford, K. L. (2003). Passive treatment systems for acid mine drainage. https://digitalcommons.unl.edu/usblmpub/19/ 
Francioso, O., Rodriguez-Estrada, M. T., Montecchio, D., Salomoni, C., Caputo, A., \& Palenzona, D. (2010). Chemical characterization of municipal wastewater sludges produced by two-phase anaerobic digestion for biogas production. Journal of Hazardous Materials, 175(1-3), 740-746. https://doi.org/10.1016/j.jhazmat.2009.10.071

Frost, R. L., Xi, Y., \& Scholz, R. (2013). Vibrational spectroscopy of the copper (II) disodium sulphate dihydrate mineral kröhnkite $\mathrm{Na}_{2} \mathrm{Cu}\left(\mathrm{SO}_{4}\right)_{2} \cdot 2 \mathrm{H}_{2} \mathrm{O}$. Spectroscopy Letters, 46(6), 447-452. https://doi.org/10.1080/00387010.2012.753906

Janczukowicz, W., Szewczyk, M., Krzemieniewski, M., \& Pesta, J. (2001). Settling properties of activated sludge from a sequencing batch reactor (SBR). Polish Journal of Environmental Studies, 10(1), 15-20. http://www.pjoes.com/Settling-properties-ofactivated-sludge-from-a-sequencing-batch-reactor-SBR-,87346,0,2.html

Johnson, D. B., \& Hallberg, K. B. (2005). Acid mine drainage remediation options: A review. $\begin{array}{llll}\text { Science } & \text { Total } & \text { Environment, } & 338(1-2),\end{array}$ https://doi.org/10.1016/j.scitotenv.2004.09.002

Mancell-Egala, A., Kinnear, D., Murthy, S., \& Jones, K. (2012). Settling transition concentration measurement to quantify sludge settling behaviour. Water Environment Federation, 5735-5746.

Mazdeh, F. M. (2014). Investigating flocculation and discrete settling behavior of activated sludge using particle size analysis. Master's dissertation. Faculty of Bioscience Engineering, University of Gent. https://pdfs.semanticscholar.org/22a5/3d34dfb7f5811af6c6777136254d352127e2.pdf

Mejía, E. R., Ospina, J. D., Osorno, L., Márquez, M. A., \& Morales, A. L. (2015). Mineralogical characterization of chalcopyrite bioleaching. In Fourier Transform-Signal Processing and Physical Sciences. Intech Open. http://dx.doi.org/10.5772/59489

Munyengabe, A., \& Zvinowanda, C. (2019). Synthesis and chemical stability studies of sodium ferrate (VI) solution. Asian Journal of Chemistry, 31(12), 3029-3034. https://doi.org/10.14233/ajchem.2019.22267

Munyengabe, A., Zvinowanda, C., Zvimba, J. N., \& Ramontja, J. (2020). Innovative oxidation and kinetic studies of ferrous ion by sodium ferrate (VI) and simultaneous removal of metals from a synthetic acid mine drainage. Physics and Chemistry of the Earth, Parts $A / B / C, 102932$. https://doi.org/10.1016/j.pce.2020.102932

Rushton, A., Ward, A. S., \& Holdich, R. G. (2008). Solid-liquid filtration and separation technology. John Wiley \& Sons. https://pdfs.semanticscholar.org/c1de/79d2989bc1f6ecd93f0f9b10a4dfdaeca560.pdf 
Samal, D. K., Sukla, L. B., Pattanaik, A., \& Pradhan, D. (2020). Role of microalgae in treatment of acid mine drainage and recovery of valuable metals. Materials Today: Proceedings. https://doi.org/10.1016/j.matpr.2020.02.165

Seo, E. Y., Cheong, Y. W., Yim, G. J., Min, K. W., \& Geroni, J. N. (2017). Recovery of Fe, $\mathrm{Al}$ and $\mathrm{Mn}$ in acid coal mine drainage by sequential selective precipitation with control of pH. Catena, 148, 11-16. https://doi.org/10.1016/j.catena.2016.07.022

Torfs, E., Nopens, I., Winkler, M., Vanrolleghem, P. A., Balemans, S., Smets, I. Y., \& Brdjanovic, D. (2016). Settling tests. Experimental Methods in Wastewater Treatment; van Loosdrecht, M., Nielsen, P., Lopez-Vazquez, CM, Brdjanovic, D., Eds, 235-262. https://modeleau.fsg.ulaval.ca/fileadmin/modeleau/documents/Publications/pvr1231.pdf Uchiyama, H., Igarashi, T., Asakura, K., Ochi, Y., Ishizuka, F., \& Kawada, S. (2007). Acid mine drainage treatment through a two-step neutralization ferrite-formation process in Northern Japan: Physical and chemical characterization of the sludge. Minerals Engineering, 20(14), 1309-1314. https://doi.org/10.1016/j.mineng.2007.08.002

Vogel, A. I., \& Jeffery, G. H. (1989). Vogel's textbook of quantitative chemical analysis. Wiley. 